\title{
THE DYNAMIC PERFORMANCE ANALYSIS OF THE FOIL BEARING STRUCTURE
}

\author{
Grzegorz ŻYWICA* \\ *Institute of Fluid-Flow Machinery, Polish Academy of Sciences, ul. Fiszera 14, 80-231 Gdańsk, Poland
}

gzywica@imp.gda.pl

\begin{abstract}
Foil bearings are a variety of slide bearings in which an additional set of foils is applied between journal and bush, in order to improve the selected static and dynamic properties. Engineers and researchers from all over the world investigate bearings of this type since many years - both from numerical as well as experimental point of view. Due to the complexity of construction, the reliable simulation models are all the time being searched for. This paper discusses the important stages of elaboration of the structural supporting layer numerical model of the foil bearing as well as results of verification tests. The main goal of the conducted study was assessment of reliability of the elaborated numerical model, in scope of dynamic properties. In the near future it will be used for elaboration of the numerical model of the entire foil bearing, which will take into account also phenomena in fluid-film layer. Those models will be used together to describe bearing system in operation.
\end{abstract}

Key words: Foil Bearings, Bearing Systems, Micro-Turbines, High-Speed Rotors

\section{INTRODUCTION}

Bearing systems based on foil bearings are the most used in lightly loaded, high-speed rotating systems. With the use of such bearings a number of benefits is associated with the operation of the machine. Comparing to conventional aerostatic bearings, foil bearings do not require a stream of compressed air supply, which is advantageous due to the energy balance of the machine. Another advantage is the large dynamic stability of rotors supported on foil bearings, which is achieved mainly thanks to the very good damping properties of the set of foils (bump foil and top foil). Increased stability of the rotor also allows the machine to operate at higher speed. In addition, bearings of this type can operate at very high temperatures reaching several hundred degrees Celsius. The advantages of foil bearings are that they are increasingly being used in machines such as: micro-turbines, turbochargers or expanders (Agrawal, 1997; Lee et al., 2012).

The main difference in the construction of conventional slide bearings and foil bearings concerns additional element of thin, contoured foils' set of high compliance (Fig. 1). This assembly is placed between the mating surfaces of the journal and bush. This allows improving the stiffness-damping properties of the support system, which has a beneficial effect on the dynamic properties of the rotor-bearing system. The use of this approach allows stable operation of the system even at very high speed, not accessible to other slide bearings. Unstable operation of a machine at high speed is often caused by the limited possibility of damping in the bearings (especially in gas bearings). In the foil bearings this issue is limited.

Discussing foil bearings we should also pay attention to their basic disadvantages that are not found in any other bearing systems. Foil bearings should be uniquely designed for each specific machine. Depending on the load, speed, lubricant, and temperature it is necessary to use a suitable materials and geometry of the compliant elements. For technological reasons, it is difficult to produce repeatable series of bearings. Bearings of this kind are installed with a small interference, well adapted for proper operation at higher speed. This results in two consecutive issues: the starting and stopping of the machine causes direct contact between the top foil and the journal, which leads to rapid wearing away the elements. The second problem is the relatively high starting torque, required to run the machine. Despite these disadvantages, in some of the aforementioned machines, foil bearings are the most suitable ones. a)
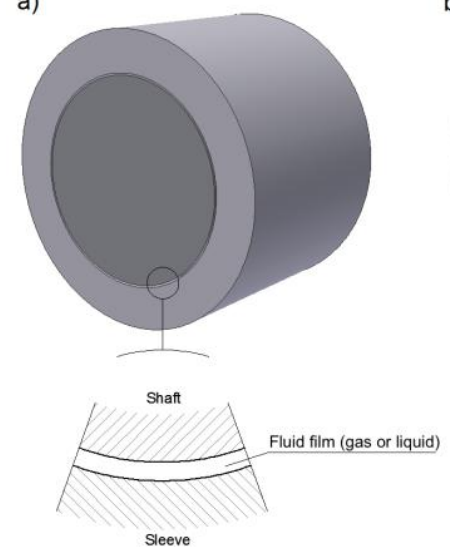

b)
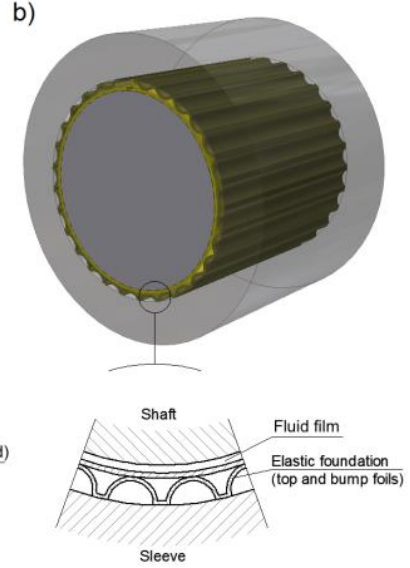

Fig. 1. The difference between a classical slide bearing (hydrodynamic or aerodynamic) (a) and a foil bearing (b)

In the world literature, in the recent years, more and more space is devoted to the research and modeling of foil bearings (DellaCorte, 1997; Lee et al., 2004; Rubio and San Andres, 2006; Kim and Park, 2009). A couple of research and industry centres have been involved in examining the subject, mainly in the United States of America. The theoretical description of the operation of foil bearings must take into consideration the many physical 
phenomena occurring in parallel and requires the search for new, reliable models. Simple analytical models fail in this case, and it is necessary to use the latest software that supports engineering calculations and advanced computer techniques. The main problem relates to an adequate description of the phenomena occurring in the geometrically complex, flexible set of foils, as well as the integration of structural analysis with the flow analysis (description of the phenomena occurring in the lubricant wedge). The appropriate description of the processes occurring in these bearing nodes should take into account: the phenomena of contact, deformations of geometrically complex set of foils, thermal phenomena, the flow of a lubricant in deformed bearing interspace and fluid-structure interactions (Selehi and Heshmat, 2000; San Andres and Kim, 2009). This brings about a difficulties often associated with the limited applications and the need to carry out calculations in parallel with several applications.

The group of scientists at the Institute of Fluid-Flow Machinery Polish Academy of Sciences have been dealing with the problematics of application and analysis of foil bearings. The results of previous studies have been included in several earlier publications (Kicinski et al., 2008; Kozanecki et al., 2009; Kicinski and Zywica, 2010; Zywica, 2011). The ongoing work is aimed at creating a complete model of the foil bearing, taking into account both structural (without geometric simplification) and flow supporting layer. This article discusses the next phase of work on the foil bearing numerical model, which aims to study the properties of dynamically loaded bearing structural layers. This is a continuation of the work described in an earlier article (Zywica, 2011), which dealt with the analysis of the same system statically loaded. Since foil bearing elements during operation are imposed by variable dynamic forces, it should be included in a bearing model. In addition to the discussion of the numerical model and simulation studies, the article also presents the results of experimental verification of the model.

\section{COMPUTATIONAL ANALYSIS}

\subsection{Numerical model of a foil bearing structure}

The complex geometry of the foils and of the bearing was prepared in a parametric program suitable for creating complex geometry - Autodesk Inventor. The parameterization of the model allowed any change in the geometry and quick adaptation of dimensions to current needs. Due to the two-dimensional nature of structural deformation of the foil bearing support layer and low computing performance of 3D models it was decided to use a two-dimensional model. This model allows a very precise analysis of the phenomena occurring in the foil bearings (first and second generation), in which there is no variation of the bump foil geometry in the axial direction. The two-dimensional model is able to reproduce the full geometry of the test bearing in a plane perpendicular to the axis of rotation and the width of the bearing is taken into account by an additional parameter. The primary dimensions and parameters of the test bearing are given on Tab. 1. They were determined on the basis of (Rubio and San Andres, 2006; Kim et al., 2009), which allowed the comparison of results. Due to the need to preserve the uniqueness of the geometry description, not so much relevant differences occurred only in the case of the output, such as the bump pitch and bump length.

The bump foil of the tested bearing composed of five identical sectors, equally spaced around the circumference of a bush.
The total number of bumps was set to 25 . The nominal clearance in the actual bearings is only approximate and, in practice, due to the pre-clamp of the bearing, it is usually determined experimentally on a special test rig (Howard and San Andres, 2010). However, it is given in the case of such bearing models, since it is necessary to draw an unambiguous geometry.

Tab. 1. Nominal dimensions, parameters and material specification of the foil bearing.

\begin{tabular}{|c|c|c|}
\hline No & Dimension/Parameter & Value \\
\hline 1 & Inner diameter & $38,17 \mathrm{~mm}$ \\
\hline 2 & Bearing length & $38,10 \mathrm{~mm}$ \\
\hline 3 & Nominal journal diameter & $38,10 \mathrm{~mm}$ \\
\hline 4 & Nominal radial clearance & $0,035 \mathrm{~mm}$ \\
\hline 5 & Number of bumps & 25 \\
\hline 6 & Bump pitch & $4,57 \mathrm{~mm}$ \\
\hline 7 & Bump length & $4,06 \mathrm{~mm}$ \\
\hline 8 & Bump height & $0,38 \mathrm{~mm}$ \\
\hline 9 & Foil thickness (top and top foil) & $0,1 \mathrm{~mm}$ \\
\hline 10 & Young's modulus & $2,1 \cdot 10^{11} \mathrm{~Pa}$ \\
\hline 11 & Poisson's ratio & 0,29 \\
\hline 12 & Density of material & $7860 \mathrm{~kg} / \mathrm{m}^{3}$ \\
\hline
\end{tabular}

FEA model of the analyzed foil bearing was developed by ABAQUS software. Due to the relatively high compliance of the foils set consisting of thin steel plates, bush and journal were treated as rigid bodies in the analysis. Therefore, these elements were simplified and replaced by the rings of a thickness that allows to apply a regular mesh. Developed FEM model is shown in Fig. 2.

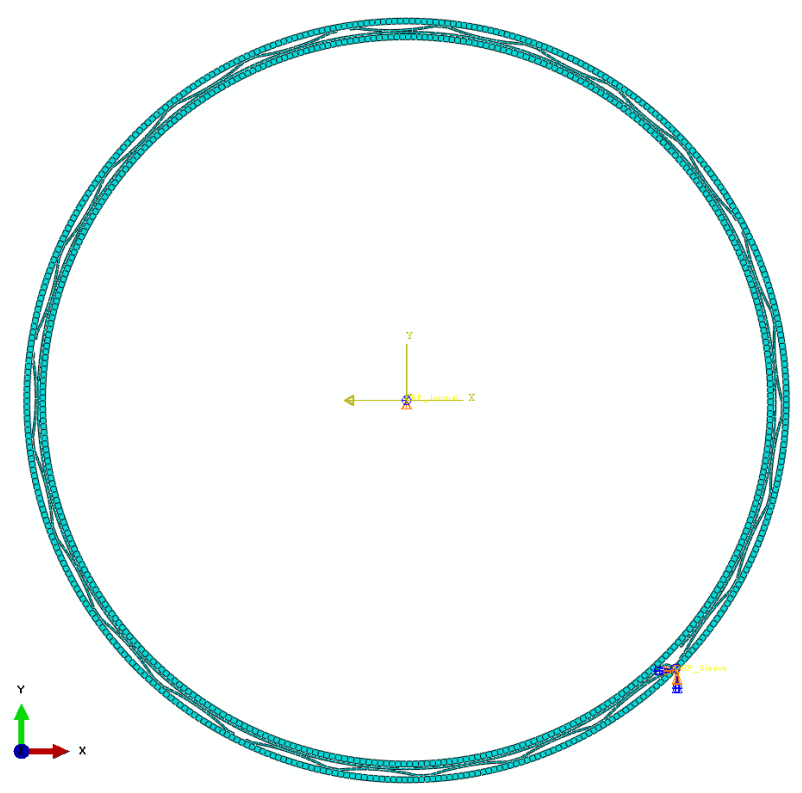

Fig. 2. FEM model of the foil bearing structure

The numerical model of the foil bearing structure presented above was composed of a total of 9778 degrees of freedom. The size and type of finite elements, FEM seeding of individual pieces of geometry, was selected by the numerical model optimization. Finally, for discretization CPE4RH type elements were 
chosen which have four nodes and first order shape functions. These elements allowed to obtain the most reliable results. The top foil and each of the five sectors of the bump foil were one-sidedly restrained. The displacements of the rest of the foil were limited by journal and bushing surfaces and interactions. Between these elements contact was modelled where friction coefficient was set to 0.1 .

\subsection{FEM calculations}

In order to determine the dynamic characteristics, based on the discussed numerical model, simulation calculations had been planned to be adapted for experimental tests conducted by Kim et al. (2009). These tests consisted of forcing vibrations of structural part of the foil bearing using electromagnetic exciter. During the experiment, the rotor was not rotating, and its function was done by the shaft rigidly mounted in the spindle lathe.The bearing sleeve was connected only with the tension member, through which harmonic excitation was transmitted from the exciter. The current value of the exciting force was measured using a force sensor that had been mounted between the tension member and the bearing sleeve. For displacement measurement the eddy current sensor was used. Schematic view of the test rig is shown in Fig. 3.

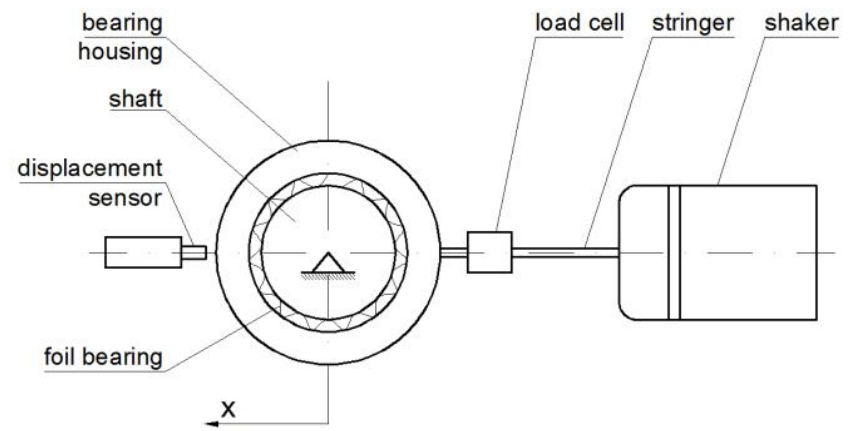

Fig. 3. Schematic view of test stand for dynamic excitation of the foil bearing

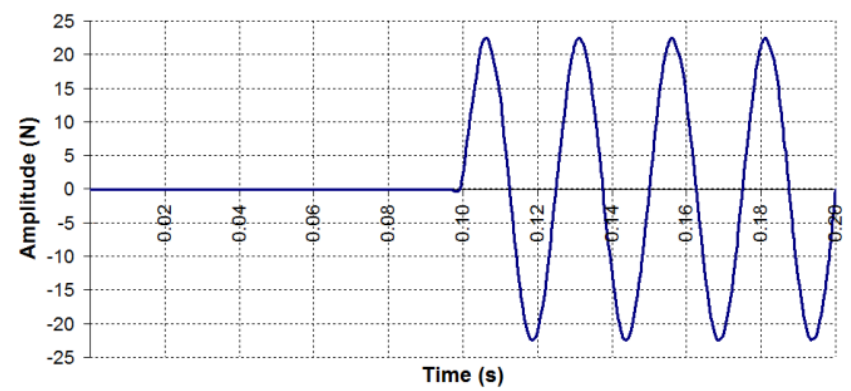

Fig. 4. The time course of the excitation force

The conditions of the experiment were reproduced during the simulations by appropriately set of boundary conditions and load. The essence of these researches relied on the determination of the relative displacements of journal and bush caused by the external load, which had been limited by the presence of foils' set and the inertia of bearing components. Therefore, in order to simplify the numerical model, external load during the analysis was applied to the journal (as in real bearing) and not to the bearing bush. The bush was fixed and unable to move in any direction. Regarding the weight of bearing components, this approach allows to obtain results that can be compared to the results of the mentioned work (Kim et al., 2009).

ABAQUS calculations focused on the dynamic response of the system in the horizontal direction (in the direction of the excitation force). The procedure 'Dynamic, Implicit' was used along with active option 'Nonlinear geometry'. Excitation frequency was $40 \mathrm{~Hz}$, and the amplitude of the exciting force $22.5 \mathrm{~N}$ (according to the experiment). The force was changing by the sine function. The total time of the dynamic analysis was $0.2 \mathrm{~s}$, while the harmonic force was active only for $0.1 \mathrm{~s}$ (from $0.1 \mathrm{~s}$ to $0.2 \mathrm{~s}$ ). Initial analysis time of $0-0.1 \mathrm{~s}$ was necessary to determine the contact conditions. The time course of force acting on the bearing is shown in Fig. 4.

The model of foil bearing structure with acting dynamic force was based on previously developed and successfully validated model presented in the previous article (Zywica, 2011). As preliminary calculations had shown, some of the parameters of the model required modifications and refinement. It was also necessary to insert additional parameters in the model, that in previous, static analysis were neglectable. The key parameter was the mass of the loaded and moving bearing component. Also important was the weight of additional components, such as the load cell, stringer, even thermocouples with cables (that were used to measure temperature). It was also found that the relatively stiff cables that were used to connect thermocouples and load cell also affected stiffness-damping properties of the system and it had to be taken into account in the model. The values of these additional parameters, which were not initially known, were chosen in the process of verification and model tuning.

\section{COMPARISON OF PREDICTED AND EXPERIMENTAL RESPONSE}

The basic criterion for assessing the usefulness of numerical models should be its reliability, which is easily determined by comparison with the real system. In the case of this model of foil bearing verification was carried out in two stages. The first stage of the verification concerned the characteristics of structural part of the bearing under static load (Zywica, 2011). In the research study (presented in this article) statically proven model was verified under a dynamic load operation.

The characteristics obtained initially in the form of displacements of the journal in the course of time and displacement versus the value of the load are shown in Fig. 5 and 6 . From the characteristics shown in Fig. 5 we can observe that the journal after applying the force was bounced off the foils, and then, under the influence of the increasing force, was again pressed into foil set. To compare the characteristics obtained with the results of the experiment described in the article (Kim et al., 2009), it was necessary to draw the graph in the configuration: the dynamic load - displacement, which is shown in Figure 6. Results determined by simulation differed significantly from the experimental curves. At higher load (above $10 \mathrm{~N}$ ) journal displacement depended only on the value of the load, regardless of whether the system was loading or unloading. In the real bearing a marked difference in displacement was observed depending on the load phase, which meant the capacity of the bearing structure to dissipate the 
energy. This indicated the need to refine the numerical model so that its characteristics were similar to the real system.

Modification of pre-tested model was started from the identification of the most relevant differences between the model and the test rig. The first potential cause could be neglecting of weight of bearing's elements, what for the static analyses conducted earlier did not matter. Additional concentrated mass was added in the journal model to its centre of gravity, but according to the experiment it reflected on the weight of bush, sensors, stringer and thermocouples with the wires. Using the description of the test rig and a series of tests the value of the additional weight was set at $0.5 \mathrm{~kg}$.

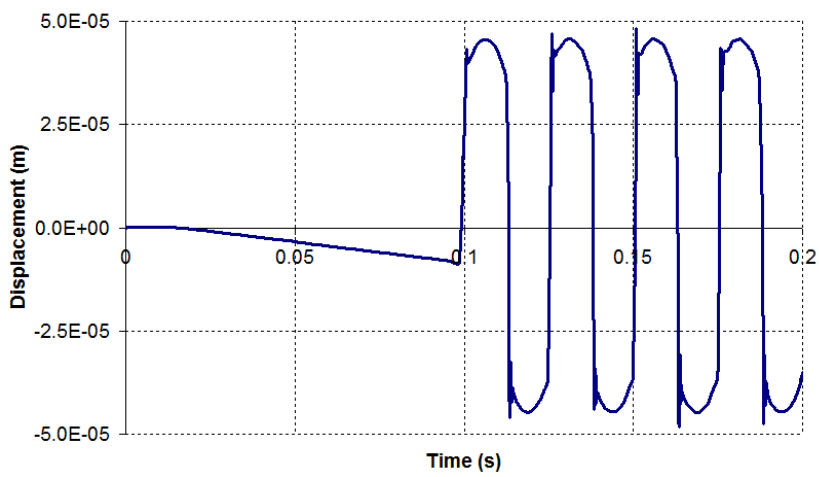

Fig. 5. Displacement of the shaft in the foil bearing at dynamic load (numerical model before validation)

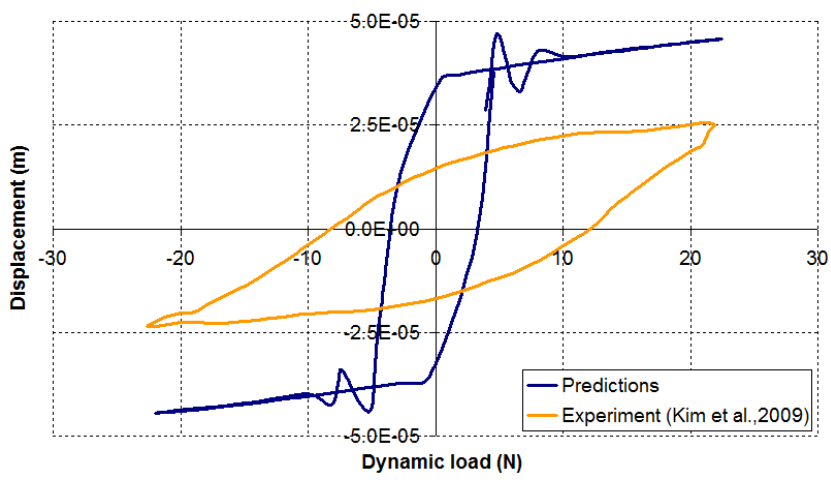

Fig. 6. Comparison of predicted and experimental displacement versus dynamic load for the foil bearing structure (predictions based on the numerical model before validation)

The described modified system still did not allow to obtain the similar characteristics to the experimental results. It was necessary to introduce the following modifications to the model involving the use of additional stiffness-damping elements that were connected to the center of journal. After many attempts optimal value of damping and stiffness was set at $D=1000 \mathrm{~N} \cdot \mathrm{s} / \mathrm{m}$ and $\mathrm{K}=4 \cdot 10^{5} \mathrm{~N} / \mathrm{m}$. Journal displacement values depending on time and the load after described modifications are shown in Fig. 7 and 8. With the implementation of an additional stiffness-damping element, a visible impact of external components attached to a vibrating bush was noticed. The pictures of the test rig indicated that the wires were of a fairly large diameter, and their stiffness in comparison to the compliant foil set could not be ignored. The bearing was therefore tested under the conditions much different from a operating conditions which are typical for rotating machnies.
Fig. 8 provides direct assessment of the reliability of developed numerical model. A direct comparison of the characteristics shows that by tuning the model, very similar waveforms were obtained. Displacements obtained by computer calculations achieved higher values for the same load but the shape of the loops obtained was very similar in the whole range of the bearing operation.

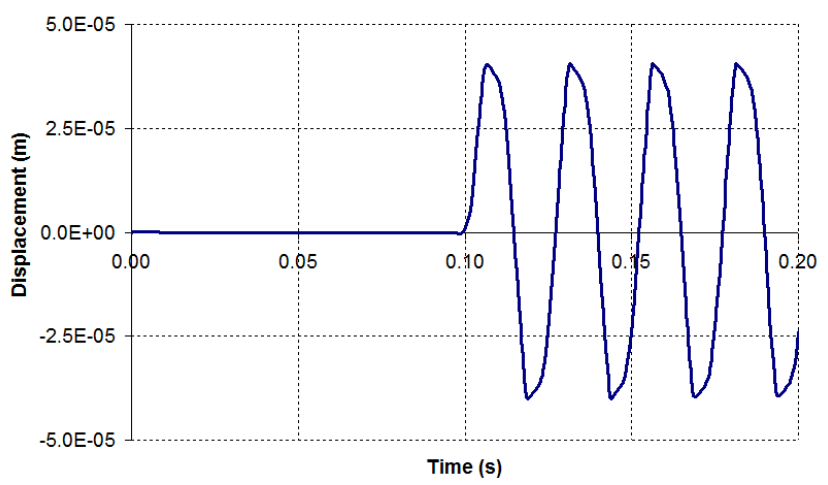

Fig. 7. Displacement of the shaft in the foil bearing at dynamic load (numerical model after validation)

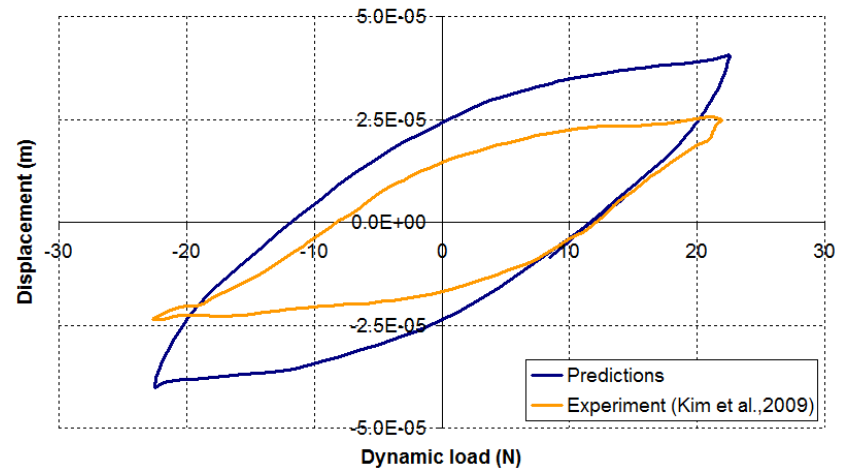

Fig. 8. Comparison of predicted and experimental displacement versus dynamic load for the foil bearing structure (predictions based on the numerical model after validation)

Due to the typical low productive precision of foil bearings and a small experimental repeatability, no further attempts were carried out in order to have even better fine-tune of the model. The discrepancies were probably caused by the way the radial clearance was included in the bearing, which does not exist in the actual design due to the initial clamp. Attempts to better tune the model can be taken after an own experimental research, in conditions more similar to those operating. As it turned out, the experimentally obtained performance was affected by several factors also not associated with the bearing, or rather with the test method used.

\section{CONCLUSIONS}

The article discusses a study to verify the foil bearing structure under dynamic loads. The following parts of this article expose the most important data for the numerical model, parameters for analysis and also the results of model verification. Modifications made during the tuning stage of the model allowed to obtain characteristics similar to the results of the experiment. Concluding 
stage of the research on the numerical model of foil bearing the developed model successfully passed the verification and can be used for further research and analysis.

In the next stage of research, the model of the foil bearing structure will be integrated with the fluid-flow model. It should be noted that the developed structural model has a very high potential in the field of reproducing the properties of a flexible foil set, because in addition to complex, nonlinear geometry of thin foils it also takes into account the phenomenon of contact between all elements of the bearing. The concept of a complete model of bearing will be based on the consideration of the fluid-structure interactions. It will be the topic of the next publications.

\section{REFERENCES}

1. Agrawal G.L. (1997), Foil air/gas bearing technology - an overview, International Gas Turbine \& Aero Engine Congress \& Exhibition, Orlando (USA).

2. DellaCorte C. (1997), A new foil air bearing test rig for use to $700{ }^{\circ} \mathrm{C}$ and 70,000 rpm, NASA TM-107405.

3. Howard S.A., San Andres L. (2010), A new analysis tool assessment for rotordynamic modeling of gas foil bearings, ASME Turbo Expo 2010: Power for Land, Sea and Air GT2010, Glasgow, UK, (GT2010-22508).

4. Kicinski J., Zywica G. (2010), The numerical analysis of the steam microturbine rotor supported on foil bearing, Advances in Vibration Engineering, Vol. 11, No. 2, 113-119.

5. Kicinski J., Zywica G., Rzadkowski R., Drewczynski M. (2008), Numerical modeling of the structural layer of foil bearing, Acta Mechanica et Automatica, Vol. 2, No. 1, 45-50.
6. Kim D., Park S. (2009), Hydrostatic air foil bearings: analytical and experimental investigation, Tribology International, Vol. 42, 413-425.

7. Kim T.H., Breedlove A.W., San Andres L. (2009), Characterization of a foil bearing structure at increasing temperatures: static load and dynamic force performance, Journal of Tribology, Vol. 131.

8. Kozanecki Z., Kicinski J., Zywica G. (2009), Numerical model of the high speed rotors supported on variable geometry bearings, IUTAM Symposium on Emerging Trends in Rotor Dynamics, New Delhi, INDIA.

9. Lee Y.B., Kim T.H., Kim C.H., Lee N.S., Choi D.H. (2004), Unbalance response of a super-critical rotor supported by foil bearings - comparison with test results, Tribology Transactions, Vol. 47, No. 1, 54-60.

10. Lee Y.B., Park D.J., Kim H.T., Sim K. (2012), Development and performance measurement of oil-free turbocharger supported on gas foil bearings, Journal of Engineering for Gas Turbines and Power, Vol. 134, Issue 3, 54-60.

11. Rubio D., San Andres L. (2006), Bump-type foil bearing structural stiffness: experiments and predictions, ASME Journal of Engineering for Gas Turbines and Power, Vol. 128, 653-660.

12. Salehi M., Heshmat H. (2000), On the fluid flow and thermal analysis of a compliant surface foil bearing and seal, Tribology Transactions, Vol. 43, No. 2, $318-324$.

13. San Andres L., Kim T.H. (2009), Analysis of gas foil bearings integrating FE top foil models, Tribology International, Vol. 42, 111-120.

14. Zywica G. (2011), The static performance analysis of the foil bearing structure, Acta Mechanica et Automatica, Vol. 5, No. 4, 119-122.

The research work was supported by project No POIG.01.03.01-00027/08 "Application intelligent materials and structures to develop and implement the concept of the innovative bearing system for power micro-turbine rotors". 